\title{
El gluten. Su historia y efectos en la enfermedad celíaca
}

\author{
ALEJANDRA PARADA ${ }^{1}$, MAGDALENA ARAYA ${ }^{2}$
}

\section{History of gluten and its effects on celiac disease}

The global prevalence of celiac disease is of one person per 250 inhabitants. The disease is induced by gluten, a peptide contained in wheat, rye and barley that during small intestinal digestion generates smaller peptides. Some of these are resistant to hydrolysis and cross through the epithelium into the mucosa, inducing a cascade of immune reactions leading to the appearance of the disease in susceptible individuals. Gluten appeared as a consequence of agricultural practices initiated 10000 years ago in the Fertile Crescent of southwest Asia. Celiac disease epidemiology is complicated since consumption of gluten differs depending on the origin of populations. Treatment of celiac disease consists of withdrawing gluten from the diet, a task that becomes difficult in the long term. The concept of gluten-free food has changed along time. This article updates the concept of celiac disease, the history of gluten consumption in the world, the characteristics of a gluten free diet and the difficulties to adhere to it.

(Rev Med Chile 2010; 138: 1319-1325).

Key words: Celiac disease; Gliadin; Glutens.

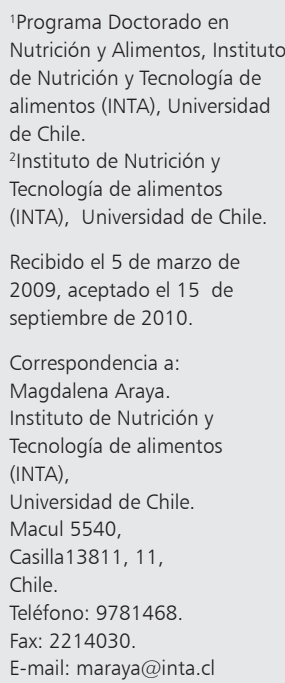

$\mathrm{L}$ os conocimientos derivados del uso creciente de anticuerpos anti-endomisio (EMA) y anti-transglutaminasa (TTG) han puesto de manifiesto que el número de celíacos es considerablemente mayor al que pensábamos y no todos los afectados presentan la sintomatología digestiva clásica. La nueva epidemiología, que incorpora a las presentaciones clínicas atípicas, estima una prevalencia promedio mundial de un celíaco por cada 250 habitantes. En Chile no existen estudios poblacionales de prevalencia utilizando serología como herramienta de búsqueda. Sin embargo, en un estudio clínico efectuado en 1994, pacientes que consultaron por sintomatología digestiva y en quienes se diagnosticó enfermedad celíaca (EC) por biopsia, la incidencia estimada fue de 1 en 1.846 personas, similar a varias descritas en Europa en la década 1980-89 ${ }^{1}$.

Es relevante conocer la frecuencia de la enfermedad celíaca por el riesgo de desarrollar algunos tipos de cáncer o enfermedades autoinmunes. Ac- tualmente no es claro cuál es riesgo de desarrollar estas complicaciones; aunque no está claramente demostrado, hay evidencias que sugieren que el riesgo se relaciona con el tiempo de exposición al gluten, lo que hace que la exposición al gluten merezca atención y estudio ${ }^{2}$. Creemos relevante poner al día a la comunidad de profesionales y a la población general sobre la relación del hombre con el gluten. En los siguientes párrafos revisaremos brevemente qué entendemos actualmente por la enfermedad, la historia del gluten en el mundo y la dieta sin gluten.

\section{$\underline{¿ Q u e ́ ~ e n t e n d e m o s ~ p o r ~ e n f e r m e d a d ~ c e l i ́ a c a ? ~}$}

Es un desorden autoinmune intestinal crónico con un fuerte componente genético, cuya sintomatología resulta de la ingestión de la proteína más importante del trigo, cebada y centeno, denominada gluten. Esta proteína induce un proceso inflamatorio crónico en el intestino delgado, que 
conduce al aplanamiento progresivo de las vellosidades intestinales, hiperplasia de las criptas e infiltración del epitelio por linfocitos, que eventualmente pueden experimentar una transformación maligna. La enfermedad es poligénica e involucra, principalmente, genes del complejo mayor de antígenos de histocompatibilidad (MHC) como HLA DQ2 y DQ8 y en menor frecuencia genes no $\mathrm{MHC}^{3}$. Existen varios genes no-MHC que estarían implicados en la susceptibilidad de la enfermedad, sin embargo la evidencia no es concluyente aún, porque los resultados difieren en los diferentes países estudiados, por ejemplo, en genes candidatos como Gen IXb de miosina (MYO9B), que altera la permeabilidad intestinal ${ }^{4}$, CTLA- 4 y otros genes reguladores (CD28 e ICOS) de linfocitos T. CTLA-4 es un co-receptor expresado en células T activadas encargado de reducir la activación de estas $^{5}$. Estudios de tamizaje de genes mediante microarrays han identificados otros genes candidatos, relacionados con la diferenciación de células epiteliales 6 . Además, estudios de GWAS (genomewide association scan) en $\mathrm{EC}$, han identificado SNPs de las regiones génicas que codifican para CCR3, IL12A, IL18RAP, RGS1, SH2B3, TAGAP7; LPP, ITGA $4^{8}$ y CCR $3^{9}$, demostrando que existen alteraciones génicas a nivel de reguladores de la respuesta inmune.

Las manifestaciones clínicas de la EC actualmente se clasifican bajo el concepto de "iceberg" celíaco $^{10}$ (Figura 1).

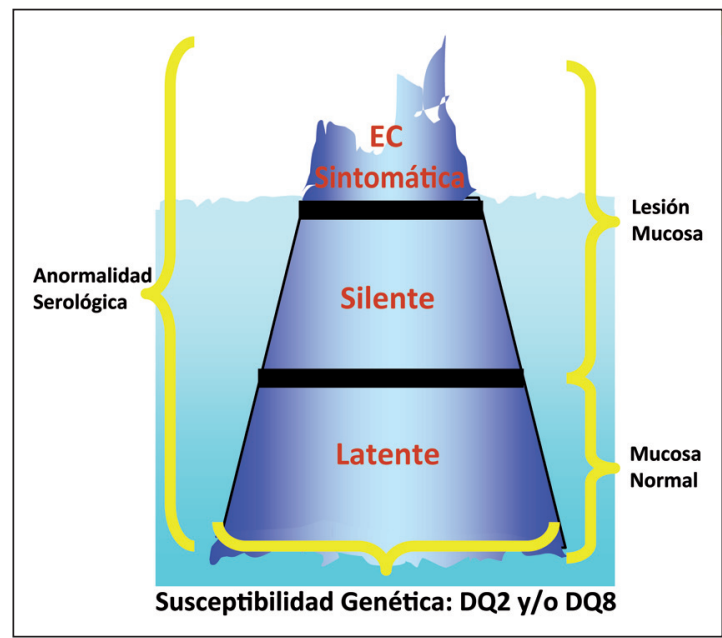

Figura 1. Manifestaciones clínicas de la enfermedad celíaca caracterizada como un Iceber. Adaptado de Catassi 1996².
La punta del iceberg está representada por los casos sintomáticos, con anticuerpos EMA o tTG positivos y que tienen lesión moderada a grave en la mucosa intestinal (presentación clásica o típica); existen también casos cuya sintomatología puede ser menor o ausente, tienen por lo menos uno de los anticuerpo positivos y tienen una lesión clara en la mucosa, estos son los llamados presentaciones silentes. Estos dos grupos comparten la característica de desarrollar una lesión intestinal evidenteEl término presentación atípica se usa cuando las manifestaciones digestivas son inespecíficas o leves y la sintomatología predominante es no digestiva. En algunos casos pueden ser consecuencia de un síndrome de malabsorción subclínico, como en el caso de anemia por deficiencia de hierro que no responde a tratamiento habitual o bien reaparece en el tiempo, osteoporosis en edades tempranas, estatura baja u otras, como infertilidad, compromiso hepático tipo hepatitis autoinmune o estrato hepatitis; en otros, predominan los procesos autoinmunes. La forma latente incluye varias situaciones: el paciente que tiene haplotipos de riesgo pero es asintomático y sus exámenes son negativos, el paciente asintomático con serología positiva (anti-tTG, EMA) pero cuya biopsia intestinal es normal ${ }^{11} \mathrm{y}$, finalmente, aquellos pacientes que fueron diagnosticados en la niñez y que puestos en desafío con gluten hasta ahora no han recaido.

Hoy día está ampliamente aceptado que la enfermedad celíaca se debe buscar activamente, ya que las formas atípicas y silentes son las más frecuentes y puede pasar desapercibida o bien confundida con otras entidades clínicas ${ }^{12}$. Esto es especialmente relevante en países de la región, donde la desnutrición calórico-proteica es prevalente en la población infantil. La aplicación de estrategias de búsqueda activa ha llevado a aumentar sustancialmente el número de casos diagnosticados.

\section{Aspectos históricos}

\section{a) Enfermedad Celíaca}

La primera descripción de la enfermedad celíaca, según Francis Adams, fue hecha por el médico Aretaeus de Capadocia en el siglo II AC, designando la enfermedad como "el que padece del intestino". Sólo en el año 1888, el patólogo inglés 
Samuel Gee describió la enfermedad en niños, usando conceptos más modernos ${ }^{13}$. Posteriormente, Dicke, pediatra holandés, demostró la relación entre la ingesta de cereales y la manifestación de síndrome de malabsorción ${ }^{14}$. Más tarde se confirmó la importancia del trigo en la génesis de la enfermedad ${ }^{15}$. Estudios posteriores de Dicke y van de Kamer establecieron la relación causa-efecto existente entre ingesta de alimentos con gluten y aparición de los síntomas de la enfermedad ${ }^{16}$, quedando establecido que el único tratamiento eficaz, vigente hasta la actualidad, es una dieta libre de gluten, mantenida estrictamente y de por vida ${ }^{15}$.

Actualmente, la prevalencia de la enfermedad en Europa y Estados Unidos de Norteamérica se estima que es de 1\%, sin embargo, en América del Sur en general y en Chile, existe escasa información sobre la prevalencia poblacional de esta enfermedad, y no se dispone de reportes de prevalencia de la enfermedad en población indígena. El primer reporte que pudimos identificar en Chile es de 1947, donde se describe en un niño un cuadro con presencia de síntomas gastrointestinales que comenzaron luego de 2 años de vida y a los 5 años ya tenía claros signos de desnutrición y patologías secundarias a la mala absorción como osteoporosis; el diagnóstico se hizo en base a clínica y exámenes radiológicos ${ }^{17}$.

\section{b) Trigo}

El homo sapiens ha estado en la tierra alrededor de cien mil años. Después de la última glaciación (hace aproximadamente 10.000 años), hubo un periodo de abundantes lluvias y formación de ríos que favorecieron las prácticas agrícolas. Se piensa que la agricultura se inició en el creciente fértil, el gran cinturón del sudoeste de Asia que incluye el sur de Turquía, Palestina, Líbano y el norte de Iraq (Figura 2), que dio origen a una gran variedad de cereales silvestres, entre ellos Triticum dicoccoides (trigo) y Hordeum spontaneum (cebada), hasta hoy frecuentemente utilizados ${ }^{18}$. Como consecuencia de esto, entre los años 9000 y 4000 AC se ampliaron los cursos de agua y se expandió la agricultura, que llegó a incluir Irlanda, Dinamarca, y Suecia ${ }^{18}$.

Inicialmente, los cultivos incluían Triticum (trigo) y Hordeum (cebada), especies genéticamente diploides, que caían espontáneamente a los terrenos. La condición diploide permitió la presencia de dos cromosomas, que a su vez originó una gran heterogeneidad genética y fenotípica, esencial para la adaptación de los granos a diferentes condiciones ambientales. Se considera que la primera formación estable del grano ocurrió unos 6000 años AC. Se postula que existe una relación entre historia de migración poblacional y tiempo de exposición al gluten, ya que la migración europea

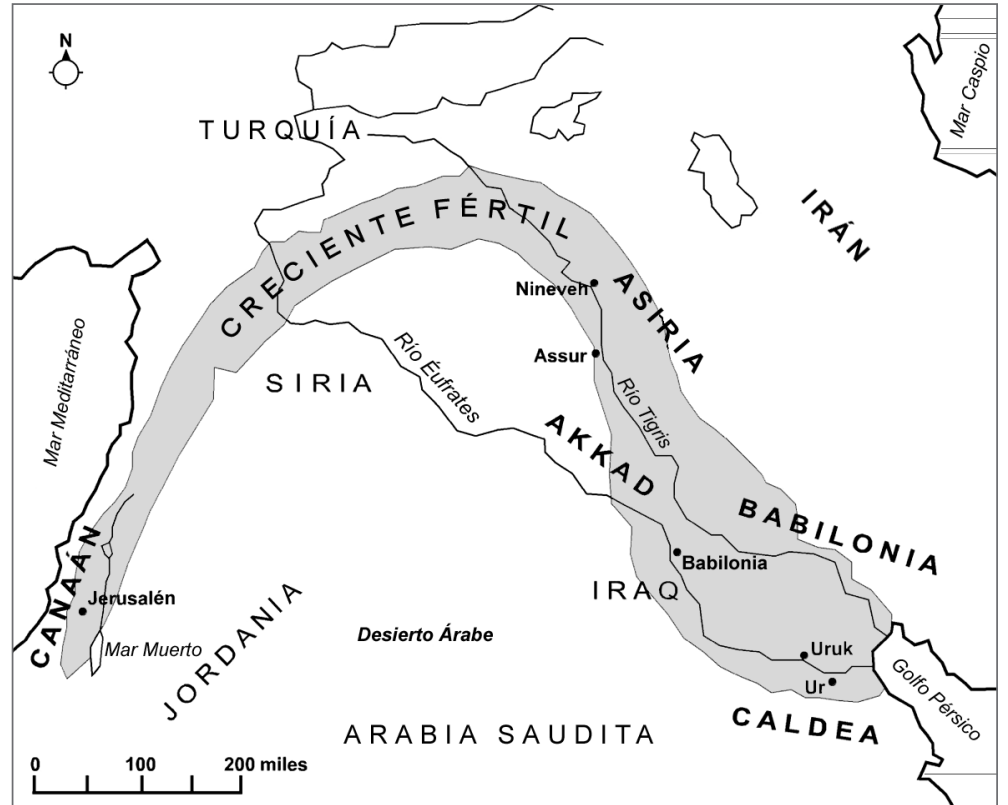

Figura 2. Creciente fértil. 
se caracterizó por una importante sustitución de las poblaciones locales mesolíticas por poblaciones neolíticas provenientes del sudoeste de Asia. Los patrones de migración de los ancestros los confirman marcadores como el haplotipo B8, del sistema de antígenos de histocompatibilidad (HLA), que revelan que la migración de los agricultores se acompañó de HLA-B8. La prevalencia de este marcador es inversamente proporcional a la duración que tiene el cultivo de trigo, existiendo menor frecuencia de HLA-B8 en las poblaciones que han convivido con el trigo por más tiempo. Estas poblaciones, genéticamente identificables por su patrón HLA específico, generaron complejos mecanismos de defensa contra el gluten, que en definitiva constituirían el origen del daño del intestino y de otros órganos ${ }^{18}$.

Sólo una pequeña área geográfica del sudoeste asiático desarrolló el cultivo de cereales que contienen gluten. En toda Asia se cultivaba el arroz, mientras que en África prevalecían el sorgo y mijo y en América el maíz, que no contienen gluten. Sin embargo, en Europa la producción de trigo, lentejas, garbanzos y arvejas era frecuente.

Es con la llegada de los europeos en el siglo XV a América que se inició la mezcla cultural, con numerosos efectos en la alimentación. Los españoles se negaban a depender de los cultivos americanos nativos, por ello se transportaba semillas de trigo desde Europa, para asegurar el abastecimiento de los alimentos habitualmente consumidos por los españoles"19.

En América precolombina, el cultivo principal y por ende el alimento básico de consumo al momento de la conquista era la papa (Solanum tuberosum) y el maíz (Zea mays), junto con la quinoa (Chenopodium quinoa), lupino (Lupinus mutabilis), así como numerosas hierbas y frutos. La carne provenía de cuys (Cavia porcellus) y los camélidos como la llama (Lama glama), alpaca (Lana pacos), vicuña (Vicugna vicugna) y guanaco (Lama guanicoe $)^{20}$. Sin embargo, los nuevos cultivos originarios de Europa aumentaron lentamente, imponiéndose sobre los productos aborígenes ${ }^{21}$.

Durante muchos siglos el consumo de gluten en Europa habría sido menor, ya que el contenido de este en los granos que consumían era bajo; sin embargo, el gran consumo de gluten está asociado a la revolución industrial con la elaboración del primer molino a vapor en el siglo XIX, así fueron evolucionando los sistemas de panificación y se añade una nueva fase a la elaboración del pan: la aireación de la masa; aparece un nuevo tipo de levadura y surgen técnicas mecánicas para amasar el pan. Con estas mejoras, la industria del pan va creciendo de manera rápida lo que contribuyó a aumentar la producción del pan y por ende su consumo. Es sólo a partir de la fabricación industrial de pan que se introdujo gluten en mayores cantidades para mejorar la calidad del producto; con esto los descendientes europeos fueron expuestos a cantidades de gluten considerable y progresivamente mayores y por ende en América ha ocurrido de igual manera en el último siglo ${ }^{22}$.

\section{El gluten, el péptido 33-mer y la cascada que lleva a la enfermedad celíaca}

El gluten es una proteína de bajo valor nutritivo, cuyo uso se masificó debido a su capacidad de retener aire en la matriz proteica facilitando que la masa se adhiera mejor, fenómeno que favorece la elaboración del pan. Las gliadinas son la fracción soluble en alcohol del gluten y contienen la mayor parte de los componentes tóxicos para los celíacos; son ricas en glutamina y prolina, cuya digestión en el tracto gastrointestinal es más difícil que el de otros péptidos ${ }^{23}$. Experimentalmente, se ha demostrado que después de digerir gliadina in vitro existen regiones sin digerir, produciéndose un péptido de $\alpha$-gliadina compuesto por 33 aminoácidos (33-mer), resistente a proteasas gástricas, pancreáticas y del borde en cepillos del intestino humano. La vida media del péptido 33-mer es mayor a 20 horas, por lo que se especula que tendría amplia oportunidad para actuar como antígeno y estimular la proliferación de células $\mathrm{T}$, induciendo fenómenos de toxicidad en los individuos genéticamente susceptibles. En experimentos también in vitro, se ha visto que los linfocitos $\mathrm{T}$ aislados de mucosa intestinal de pacientes celíacos no tratados reconocen un péptido semejante al $33 \alpha$-gliadina ${ }^{24}$.

Se desconoce cómo ocurre el paso de estos péptidos parcialmente digeridos a través de la barrera epitelial del intestino. Se postula que su paso podría estar favorecido por infecciones tempranas que aumenten transitoriamente la permeabilidad. El paso de péptidos también podría estar mediado por la acción de la zonulina, proteína que conduce señales intracelulares que abren las uniones estrechas intestinales ("tight junctions"). Se ha demos- 
trado que la gliadina induce liberación de zonulina, con aumento de la permeabilidad intestinal y producción de citoquinas ${ }^{25}$. Una vez traspasada la barrera epitelial del intestino, el fragmento de 33-mer actuaría como sustrato para la transglutaminasa 2 (tTG2) que lo deamidaría, cambiando la carga positiva a negativa en la molécula, lo que dejaría expuestos tres epítopes localizados alrededor de tres residuos de glutamato. Por otra parte, es la acción gliadina-tTG2 en sujetos susceptibles la que lleva al desarrollo de los autoanticuerpos EMA y TTG, que constituyen actualmente las herramientas más sensibles y específicas disponibles para el diagnóstico. El fragmento 33-mer modificado por la tTG2 es un eficiente estimulador de los linfocitos T CD4, que reconocerán a los péptidos del gluten solamente en presencia de los heterodímeros HLADQ2 y HLA-DQ8. La estimulación de los linfocitos lleva, de manera aun no establecida, a la cascada inmune que resulta en la respuesta inflamatoria y daño de la mucosa propia del celíaco ${ }^{26}$.

\section{Tratamiento y dieta sin gluten}

Está ampliamente demostrado que el tratamiento de la enfermedad celíaca es la dieta libre de gluten, estricta y por toda la vida ${ }^{27}$. Es importante aclarar que "dieta libre de gluten" significa que la cantidad de éste en el alimento está por debajo de un determinado punto de corte y no necesariamente que no contiene gluten. La reglamentación internacional obedece al Codex alimentarius, creado por la Organización Mundial de la Salud (OMS) y la Organización de Naciones Unidas para la Agricultura y la Alimentación (FAO), ha cambiado en el año 2009 y ha disminuido la cantidad límite de gluten que pueden contener los productos para que sean libres de gluten. Es así como califica a todo alimento libre de prolaminas tóxicas, a todo aquel producto que además de no contener bajo ninguna circunstancia rastros de cereales peligrosos para los celíacos, como lo son el trigo, la avena, la cebada, el centeno y derivados debe cumplir con el requisito que determina que la cantidad máxima de gluten admisible es 20 miligramos por kilogramo de producto $(\mathrm{mg} / \mathrm{kg})$, o dicho de otra manera, menos de 20 partes por millón $(\mathrm{ppm})^{28}$. Por ello, la Comunidad Europea ha aceptado esta sugerencia como normativa para el 2012 y considerará que los productos aceptados como libres de gluten pueden contener uno o más ingredientes que sustituyan el trigo, el centeno, la cebada, la avena o sus variedades híbridas, pero con un nivel de gluten que no supere los $20 \mathrm{ppm}$ (o mg/kg) en los alimentos(29).

Las decisiones del Codex Alimentarius son aplicadas por los distintos países adaptándolas a sus realidades. En Chile, el Ministerio de Salud define que un alimento libre de gluten es aquel que está preparado únicamente con ingredientes que por su origen natural y por la aplicación de buenas prácticas de fabricación, que impidan contaminación cruzada, no contiene prolaminas procedentes de trigo, de todas las especies de tritricum, kamut, trigo duro, centeno, ni sus variedades cruzadas, así como también la avena. A partir de octubre de 2009 la norma otorga al Instituto de Salud Pública la facultad de definir la normativa y técnicas para certificar a alimentos como libres de gluten, que actualmente pone el límite de gluten contenido en los alimentos definidos como exentos de gluten en "cantidades menores de 1 a 1,5 ppm de prolaminas, que deberán corresponder a los límites de determinación para gluten de las técnicas de laboratorios que se usan en Chile" (Chirdo y Méndez $)^{30}$.

\section{¿Cuánto gluten es mucho gluten?}

Está ampliamente demostrado que la enfermedad celíaca es gatillada por el gluten, y la cantidad mínima de gluten necesaria para inducir la aparición de síntomas no está aún del todo clara. En población no celíaca la ingesta promedio de gluten es 10 a 20 g por día ${ }^{31}$; en los celíacos, dosis sobre 1 g de gluten día producen aparición de daño severo en la mucosa intestinal ${ }^{32}$. Al infundir gliadina en dosis entre 10 a $1.000 \mathrm{mg}$ no fraccionada en el duodeno de pacientes celíacos se demostró que 10 mg de gliadina durante 8 horas no causaron daño histológico en la mucosa, $100 \mathrm{mg}$ indujeron cambios mínimos y con $500 \mathrm{mg}$ se desarrollaron cambios claros, en la relación altura vellosidad/cripta e infiltración de linfocitos intraepiteliales ${ }^{33}$. Datos posteriores mostraron que la infusión de $1.000 \mathrm{mg}$ de gliadina por 2-3 horas produjo anormalidades marcadas después de 2 a 3 horas de infusión ${ }^{34}$. Otro estudio evaluó 20 niños celíacos que recibieron $100 \mathrm{mg}$ o $500 \mathrm{mg}$ de gliadina durante 4 semanas. Los dos grupos mostraron cambios, pero el au- 
mento en cantidad de linfocitos interepiteliales y el daño histológico observado fue mayor que en el grupo que recibió $500 \mathrm{mg}^{35}$. Recientemente, el mismo autor evaluó dosis más pequeñas de gluten observando que, aunque existe variabilidad individual en la respuesta, dosis menores a $50 \mathrm{mg}$ diarios de gluten no inducen cambios significativos en la mucosa intestinal, pero $50 \mathrm{mg}$ o mas de gluten/día sí lo logran ${ }^{36}$. No es fácil traducir estos resultados a indicaciones concretas ya que los tiempos de duración de los estudios mencionados son cortos, y no hay evidencias que permitan afirmar o descartar que los resultados sean distintos cuando la exposición al gluten es a dosis bajas pero por períodos prolongados. La mayoría de los expertos en el tema están de acuerdo en que las cantidades seguras se encuentran en algún punto entre 10 y 50 ppm. Medidas extremas como menos de 10 ppm o 0 ppm, teóricamente mejores, atentan contra la mayor disponibilidad de alimentos libres de gluten (encarecen los procesos de elaboración, se certifican menos alimentos como libres de gluten) $y$, no necesariamente contribuyen al bienestar de los celíacos.

En un estudio reciente, prospectivo, aleatorio, que comparó dietas que aportaban en promedio menos de $100 \mathrm{mg}$ de gluten, una como dieta natural libre de gluten y la otra como dieta que contenía productos con almidón de trigo "exento de gluten" (distribuidos en Europa y no en Chile), que se sabe que tiene algún grado de contaminación. Se encontró similar recuperación clínica e histológi$\mathrm{ca}^{37}$, lo que han tomado como base los grupos de pacientes que optan por ampliar la dieta ${ }^{38}$. Dado que los estudios que se usan para calificar ciertas dosis diarias de gluten como seguras porque no indujeron daño histológico son escasos y de corta duración ${ }^{39}$, parece razonable adscribirse a los criterios mas estrictos, que buscan minimizar la ingesta de gluten, a pesar que esto resulte mas difícil de aceptar por parte de ciertas agrupaciones de celíacos.

\section{Referencias}

1. Araya M. Mejorar el manejo de la enfermedad celíaca. Un dasafío urgente. Rev Med Chile 2006; 134: 361-4.

2. Cosnes J, Cellier C, Viola S, Colombel J, Michaud L, Sarles J, et al. Incidence of autoimmune diseases in celiac disease: protective effect of the gluten-free diet. Clin
Gastroenterol Hepatol 2008; 6: 753-8.

3. Green P, Jabri B. Coeliac disease. The Lancet 2003; 362: 383-91.

4. Monsuur AJ, De Bakker PI, Alizadeh BZ, Zhernakova A, Bevova MR, Strengman E, et al. Myosin IXB variant increases the risk of celiac disease and points toward a primary intestinal barrier defect. Nat Genet 2005; 37: 1341-4.

5. Van Heel D, Hunt K. Genetics in coeliac disease. Best Practice \& Research Clinical Gastroenterology 2005; 19: 323-39.

6. Bracken S, Byrne G, Kelly J, Jackson J, Feighery C. Altered gene expression in highly purified enterocytes from patients with active coeliac disease. BMC Genomics 2008; 9: 377.

7. Hunt KA, Zhernakova A, Turner G, Heap GA, Franke L, Bruinenberg $M$, et al. Newly identified genetic risk variants for celiac disease related to the immune response. Nat Genet 2008; 40: 395-402.

8. Garner CP, Murray JA, Ding YC, Tien Z, Van Heel DA, Neuhausen SL. Replication of celiac disease UK genomewide association study results in a US population. Hum Mol Genet 2009; 18: 4219-25.

9. Dema B, Martínez A, Fernández-Arquero M, Maluenda C, Polanco I, De La Concha EG, et al. Association of IL18RAP and CCR3 with coeliac disease in the Spanish population. J Med Genet 2009; 46: 617-9.

10. Catassi C, Fabiani E, Rätsch IM, Coppa GV, Giorgi PL, Pierdomenico R, et al. The coeliac iceberg in Italy. A multicentre antigliadin antibodies screening for coeliac disease in school-age subjects. Acta Paediatr Suppl 1996; 412: 29-35.

11. FASANO, A. Clinical presentation of coeliac disease in the pediatrics population. Gastroenterology 2005; 128 : S68-S73

12. Green P. The many faces of coeliac disease: Clinical presentation of celiac disease in the adult population. Gastroenterology 2005; 128: S74-8.

13. Dowd B, Walter-Smith J. Samuel Gee, Arteus, and The Coeliac Affectin. British Medical Journal 1947; 2: 45-7.

14. Haas SV. Celiac disease. N Y State J Med 1963; 1: 134650.

15. Paveley W. From Arataeus to Crosby: a History of coeliac disease. British Medical Journal 1988; 297: 24-31.

16. Smits BJ. History of coeliac disease. BMJ 1989; 298: 387.

17. Meneghello J, Undurraga O. Síndrome celíaco. Rev. chil. Pediatr 1946; 17: 325-33.

18. Greco L. From the Neolithic Revolution to Gluten Intolerance: Benefits and Problems Associated with the Cultivation of Wheat. Journal of Pediatric Gastroenterology \& Nutrition 1997; 24: 14-7. 
19. Bethell L. Historia de América Latina. Editorial Crítica, Barcelona, España, 1990. p. 135.

20. Bourges H, Bengoa J, O’Donnell A. Historia de la nutrición. Sociedad Latinoamericana de Nutrición, 2009. http://www.slan.org.mx/docs/HistNut_SLAN.pdf

21. Bauer A. Alimentación y agricultura en la América colonial española. En: Castillero A. Historia General de América Latina. V III. Ediciones UNESCO, Editorial Trotta, 2000. p.177.

22. Belderok B. Developments in bread-making processes. Plant Foods Hum Nutr. 2000;55:1-86

23. Shan L, Molberg O, Parrot I, Hausch F, Filiz F, Gray GM, et al. Structural basis for gluten intolerance in celiac sprue. Science 2002; 297: 2275-9.

24. Arentz-Hanzen H, Korner R, Molberg O. Quarsten H, Vader W, Kooy YM, et al. The intestinal T cell response to alpha-gliadin in adult celiac disease is focused on a single deamidated glutamine targeted by tissue transglutaminase. J Exp Med 2000; 191: 603-12.

25. Fasano AA. Intestinal zonulin: open sesame!. Gut 2001; 49: 159-62.

26. Green PH, Jabri B. Coeliac disease. Lancet 2003; 362: 383-91.

27. Fasano A, Catassi C. Current approaches to diagnosis and treatment of celiac disease: an evolving spectrum. Gastroenterology 2001; 120: 636-51.

28. Codex-Alimentarius-Commission. Codex Standard. Joint FAO WHO Food Standards Programme. Rome: WHO, 1981: 118.

29. http://eur-lex.europa.eu/LexUriServ/LexUriServ.do?uri= OJ:L:2009:016:0003: 0005:ES:PDF

30. www.minsal.cl

31. Van Overbeek FM, Uil-Dieterman I, Mol IW, KöhlerBrands L, Heymans H, Mulder CJJ. The daily gluten intake in relatives of patients with celiac disease com- pared with that of the general Dutch population. Eur J Gastroenterol Hepatol 1997; 9: 1097-9.

32. Laurin P, Wolving M, Fälth-Magnusson K. Even small amounts of gluten cause relapse in children with celiac disease. J Pediatr Gastroenterol Nutr 2002; 34: 26-30.

33. Ciclitira P, Evans D, Fagg N, Lennox E, Dowling R. Clinical testing of gliadin fractions in coeliac patients. Clin Sci 1984; 66: 357-64.

34. Ciclitira PJ, Ellis HJ, Fagg NL. Evaluation of a gluten free product containing wheat gliadin in patients with coeliac disease. Br Med J. 1984;289:83.

35. Catassi C, Rossini M, Rätsh IM, Bearzi I, Santinelli A, Castagnani R, et al. Dose dependent effects of protracted ingestion of small amounts of gliadin in coeliac disease children: a clinical and jejunal morphometric study. Gut 1993; 34: 1515-9.

36. Catassi C, Fabiani E, Iacono G, D'Agate C, Francavilla $\mathrm{R}$, Biagi F, et al. A prospective, double-blind, placebocontrolled trial to establish a safe gluten threshold for patients with celiac disease. Am J Clin Nutr 2007; 85: 160-6.

37. Peraaho M, Kaukinen K, Paasikivi K, Sievanen H, Lohiniemi S, Maki M, et al. Wheat-starch-based gluten-free products in the treatment of newly detected coeliac disease: prospective and randomized study. Aliment Pharmacol Ther 2003; 17: 587-94.

38. Collin P, Thorell L, Kaukinen K, Maki M. The safe threshold for gluten contamination in gluten-free products. Can trace amounts be accepted in the treatment of coeliac disease?. Aliment Pharmacol Ther 2004; 19: 1277-83.

39. Hischenhuber C, Crevel R, Jarry B, Maakis M, MoneretVautrin D, Romano A, et al. Review article: safe amounts of gluten for patients with wheat allergy or coeliac disease. Aliment Pharmacol Ther 2006; 23: 559-75. 